\title{
Caracterização físico-química e tecnológica da farinha de soja integral fermentada com Aspergillus oryzae
}

\author{
Physicochemical and technological characterization of \\ whole soybean flour fermented by Aspergillus oryzae
}

\section{Autores | Authors}

\section{\ Leomar Hackbart da SILVA \\ Universidade Federal do Pampa (UNIPAMPA) Curso de Ciência e Tecnologia de Alimentos \\ Campus de Itaqui \\ Rua Luiz Joaquim de Sá Britto, s/n CEP: 97650-000 Itaqui/RS - Brasil \\ e-mail: leomarsilva@unipampa.edu.br}

Paula Fernanda Pinto da COSTA

Universidade Federal do Pampa (UNIPAMPA) Curso de Ciência e Tecnologia de Alimentos Itaqui/RS - Brasil

e-mail:paulacosta@unipampa.edu.br

Gabriela Wakayama NOMIYAMA Ingrid Paula de SOUZA Yoon Kil CHANG

Universidade Estadual de Campinas (UNICAMP)

Faculdade de Engenharia de Alimentos Campinas/SP - Brasil e-mail:gab-wn@hotmail.com ingridpsj@yahoo.com.br yokic@fea.unicamp.br

$\triangle$ Autor Correspondente / Corresponding Author

Recebido / Received: 03/05/2011 Aprovado / Approved: 31/07/2012 Publicado / Published: dez./2012

\section{Resumo}

Neste trabalho, estudou-se o efeito das condições de fermentação da farinha de soja integral, utilizando-se o fungo Aspergillus oryzae, sobre as características físico-químicas e as propriedades tecnológicas da farinha de soja integral autoclavada fermentada. A farinha de soja integral autoclavada foi fermentada com o fungo Aspergillus oryzae CCT 4359, incubada às temperaturas de $30^{\circ} \mathrm{C}$ e $40{ }^{\circ} \mathrm{C}$ por 24 horas e 48 horas, e seca em estufa a vácuo, a $60{ }^{\circ} \mathrm{C}$, até $10 \%$ de umidade final, obtendo-se a farinha de soja integral autoclavada fermentada. Esta farinha foi avaliada quanto aos seguintes aspectos: composição centesimal, índice de absorção de água, índice de solubilidade do nitrogênio, índice da atividade ureática, $\mathrm{pH}$, índice de acidez do extrato etéreo e cor instrumental. Os resultados indicaram que a fermentação aumentou o conteúdo de proteínas e lipídeos, reduzindo o teor de carboidratos, e não alterou os teores de cinzas, fibras e a umidade. Além disso, aumentou o índice de acidez do extrato etéreo, reduziu os índices de absorção de água, de solubilidade do nitrogênio e da atividade ureática, o qual passou de 0,61 para 0,26 unidades de pH (após fermentação a $30{ }^{\circ} \mathrm{C}$ e $40{ }^{\circ} \mathrm{C}$, por 48 horas), o que indica a redução de fatores antinutricionais. A fermentação, porém, não influenciou a cor e o pH. O processo de fermentação promoveu modificações nas propriedades nutricionais e tecnológicas da farinha de soja integral, ampliando seu potencial de utilização na produção de alimentos mais saudáveis para o consumidor.

Palavras-chave: Aspergillus oryzae; Farinha de soja; Fermentação.

\section{Summary}

This work studied the effect of the fermentation conditions of whole soybean flour by the mould Aspergillus oryzae on the physical and chemical characteristics and technological quality of the whole autoclaved soybean flour. The whole autoclaved soybean flour was fermented by the mould Aspergillus oryzae CCT 4359 at $30{ }^{\circ} \mathrm{C}$ and $40{ }^{\circ} \mathrm{C}$ for 24 and 48 hours, and then dried to $10 \%$ moisture content in a vacuum oven at $60^{\circ} \mathrm{C}$, thus obtaining whole fermented autoclaved soybean flour. The following characteristics were evaluated: proximate composition, water absorption index, soluble nitrogen index, ureatic activity index, $\mathrm{pH}$, ether extract acidity index and instrumental colour. The results indicated that fermentation increased the protein and lipid contents, reduced the carbohydrate content and did not alter the ash, fibre and moisture contents. It increased the ether extract acidity index and reduced the water absorption, soluble nitrogen and ureatec activity indexes, reducing the last index from 0.61 to $0.26 \mathrm{pH}$ units (after fermentation at $30{ }^{\circ} \mathrm{C}$ and $40{ }^{\circ} \mathrm{C}$ for 48 hours), indicating a reduction in the anti-nutritional factors, but did not influence the colour or $\mathrm{pH}$. The fermentation process modified the physicochemical, technological and nutritional properties of the whole soybean flour, widening its potential for the development of healthier products for the consumer.

Key words: Aspergillus oryzae; Soybean flour; Fermentation. 


\section{Introdução}

A soja Glicine Max (L.) Merril é o principal produto agrícola de exportação do Brasil, com uma produção de aproximadamente 57 milhões de toneladas em 2009, colocando o País na posição de segundo maior produtor e exportador mundial (CONAB, 2009; USDA, 2009). Além da grande importância econômica, a soja também apresenta características nutricionais e funcionais que ampliam sua aplicação em diversos tipos de alimentos (PENHA et al., 2007).

$\mathrm{Na}$ alimentação humana, em virtude do elevado potencial de produção, do baixo custo e do alto valor nutricional, a soja tem se destacado como importante fonte proteica vegetal, sendo seus principais produtos: a farinha, o isolado e o concentrado proteico de soja, os quais são utilizados principalmente como melhoradores tecnológicos de alimentos industrializados (LIU, 2005). As propriedades funcionais, como o teor de isoflavonas e peptídeos bioativos, e as características tecnológicas destes produtos - solubilidade, capacidade de geleificação, emulsificação, absorção de água e índice de solubilidade do nitrogênio - podem ser modificadas em função das condições de processamento, como aplicação de calor, germinação e/ou fermentação, além das condições de armazenamento (MOURA et al., 2007; MACHADO et al., 2008; PAUCAR-MENACHO et al., 2010; SILVA et al., 2011).

Estudos demonstraram que a fermentação pode promover a hidrólise de proteínas, formando peptídeos e reduzindo os fatores antinutricionais, o que aumenta os seus efeitos benéficos à saúde (HONG et al., 2004). A utilização de soja fermentada na alimentação humana é bastante comum nos países orientais, como Japão e China, e atualmente se tem percebido um crescente consumo dos produtos de soja fermentada em países europeus e nos Estados Unidos, em razão do incremento de compostos funcionais, como as isoflavonas agliconas e os peptídeos bioativos, que apresentam maior potencial de benefícios à saúde (MEJIA e LUMEN, 2006). Entretanto, este consumo é reduzido quando comparado ao dos países orientais, pois, em geral, a população não apresenta o hábito de consumir produtos tradicionais de soja fermentada em função de não estar acostumada com as suas características sensoriais.

A caracterização tecnológica da farinha de soja fermentada, quanto às alterações de solubilidade, capacidade de geleificação, emulsificação, absorção de água e índice de solubilidade do nitrogênio, pode ser uma alternativa para viabilizar a utilização da soja fermentada na alimentação dos países ocidentais. As possíveis alterações provocadas nas propriedades tecnológicas da farinha de soja podem influenciar a sua utilização como ingrediente em produtos para alimentação humana, com possiblidade de ser utilizada em produtos de panificação, pães e biscoitos, os quais são bem aceitos por essa população, além de conferir novas características tecnológicas, nutricionais e sensoriais. Este trabalho objetivou avaliar o efeito das condições de fermentação, utilizando-se o fungo Aspergillus oryzae na farinha de soja integral, sobre as características físico-químicas e as propriedades tecnológicas da farinha de soja integral fermentada.

\section{Material e métodos}

\subsection{Material}

Os grãos de soja, cultivar BRS 232, adquiridos da empresa Brejeiro S/A - Orlândia-SP, foram transformados em farinha de soja integral (FSI) pelo processo de moagem, em moinho de facas (marca Marconi, modelo MA580, Piracicaba-SP, Brasil). A cepa do fungo filamentoso Aspergillus oryzae (Ahlburg) Cohn, anamorph CCT 4359, foi adquirida da Coleção de Culturas Tropicais - Fundação Tropical de Pesquisas e Tecnologia André Tosello (São Paulo, Brasil).

\subsection{Métodos}

\subsubsection{Preparo do inóculo}

O inóculo foi preparado a partir de uma suspensão de esporos, cuja concentração foi de $10^{7}$ esporos. $\mathrm{mL}^{-1}$; esta foi obtida por meio de um repique do microrganismo conservado em tubos de ensaio contendo meio PDA (potato-dextrose-ágar), cultura estoque, para outros tubos de ensaio, com auxílio de uma alça metálica.

Os tubos foram incubados a $30^{\circ} \mathrm{C}$ por 4 dias; após esta etapa, foram adicionados $3 \mathrm{~mL}$ de água destilada esterilizada, agitou-se para a formação da suspensão de esporos, sendo o conteúdo de cada tubo transferido, assepticamente, para um Erlenmeyer de $250 \mathrm{~mL}$ contendo $100 \mathrm{~mL}$ de meio PDA e incubados a $30^{\circ} \mathrm{C}$ por mais 6 dias, para a esporulação do microrganismo sobre a superfície do meio de cultura.

Após esse período, em cada Erlenmeyer, foram adicionados $50 \mathrm{~mL}$ de uma solução de Tween 40 (Altas Chemical Industries, Inc.), na concentração de $15 \mathrm{mg} \cdot \mathrm{L}^{-1}$, e mais um conjunto de pérolas de vidro, agitando-se por um minuto e transferindo-se o conteúdo para um Erlenmeyer vazio e esterilizado. Após a homogeneização, retirou-se uma alíquota da suspensão para a contagem de esporos pelo método de placas (PAMBOUKIAN, 1997). A suspensão de esporos obtida apresentou uma concentração de $1,85 \times 10^{7}$ esporos. $\mathrm{mL}^{-1}$.

\subsubsection{Processo de fermentação da farinha de soja}

A farinha de soja foi submetida à fermentação semissólida, utilizando-se frascos de Erlenmeyer de 
$500 \mathrm{~mL}$, contendo $200 \mathrm{~g}$ de FSI. Após a esterilização a $121^{\circ} \mathrm{C}$, por 20 minutos, e a redução da temperatura, a amostra foi ajustada para $35 \%$ de umidade inicial, utilizando-se água destilada esterilizada e inoculada com $2 \mathrm{~mL}$ de suspensão de esporos ( $10^{7}$ esporos. $\mathrm{mL}^{-1}$ ) do fungo Aspergillus oryzae CCT 4359 (PARK et al., 2001; HONG et al., 2004).

A incubação do fungo foi realizada em estufa modelo BOD, nas temperaturas de $30^{\circ} \mathrm{C}$ e $40{ }^{\circ} \mathrm{C}$, por 24 e 48 horas. Ao final da etapa de fermentação, as amostras de farinha de soja integral autoclavada fermentada (FSIAF) foram secas em estufa a vácuo, à temperatura de $60^{\circ} \mathrm{C}$, até atingir umidade final de $10 \%$, sendo trituradas em micromoinho tipo ciclone (modelo MA020, marca Marconi) para obtenção da FSIAF (AGUIAR e PARK, 2004; HONG et al., 2004).

\subsubsection{Caracterização físico-química e cor instrumental}

As amostras de FSI, farinha de soja integral autoclavada (FSIA) e FSIAF obtidas nos diferentes tratamentos foram caracterizadas quanto à composição química centesimal pela determinação dos teores de umidade (44-31 da AACC, 2000); proteínas (46-13A da AACC, 2000); lipídeos (30-26 da AACC, 2000); cinzas (08-12 da AACC, 2000) e fibra bruta (32-10 da AACC, 2000). O teor de carboidrato foi determinado por diferença, sem considerar o teor de fibra, que faz parte dos carboidratos.

O índice de acidez do extrato etéreo foi determinado segundo o método número 58-15 da AACC (2000) e o $\mathrm{pH}$ foi avaliado de acordo com as normas analíticas do Instituto Adolfo Lutz (IAL, 1985), após o processo de fermentação em cada tratamento.

A cor instrumental das matérias-primas FSI, FSIA e FSIAF foi avaliada pelo sistema de cor CIEL $^{*} a^{*} b^{*}$, utilizando-se espectrofotômetro, marca HUNTER LAB (Reston, Va, EUA), modelo Color Quest II, considerando-se os seguintes parâmetros de operação: ângulo de visão $10^{\circ}$, iluminante $\mathrm{D} 65$ e modo de calibração RSIN (reflectância especular incluída), determinando-se os valores de $L^{*}$ ou luminosidade (preto 0/branco 100), $a^{*}$ (verde -/vermelho +) e b* (azul -/amarelo +) (MINOLTA, 1994). O croma ( $\left.C^{*}\right)$ e o ângulo de tonalidade (hab) das amostras foram calculados, respectivamente, por meio das Equações 1a e 1b:

$C^{*}=\left[\left(a^{*}\right)^{2}+\left(b^{*}\right)^{2}\right]^{1 / 2}$

hab $=\tan ^{-1}\left[b^{*} / a^{*}\right]$

\subsubsection{Avaliação tecnológica da proteína de soja e fatores antinutricionais}

As propriedades tecnológicas das proteínas de soja e os fatores antinutricionais (atividade ureática), antes e após o processo de fermentação, foram avaliados por meio da determinação dos seguintes parâmetros: índice de absorção de água (IAA) (método da AACC 88-04, 2000); índice de solubilidade de nitrogênio (ISN) (método da AACC 46-23, 2000) e índice de atividade ureática (IAU) (método da AACC 22-90, 2000).

\subsubsection{Análise estatística}

O programa estatístico Statistica verão 5.5 (Statsoft, Tulsa, OK, USA) foi utilizado para fazer a análise de variância (ANOVA). O teste de Tukey foi utilizado para determinar as diferenças entre os tratamentos (nível de significância $p \leq 0,05$ ).

\section{Resultados e discussão}

\subsection{Caracterização físico-química da matéria-prima}

A composição centesimal da FSI, da FSIA e da FSIAF, submetidas a diferentes condições de temperatura e tempo de incubação, está apresentada na Tabela 1. Observou-se que os valores médios de umidade, proteína bruta, lipídeos, cinzas, carboidratos e fibra bruta das amostras FSI e FSIA não apresentaram diferenças significativas e estão de acordo com os valores observados na literatura (PENHA et al., 2007). Estudos realizados por Moura et al. (2007) também utilizaram a autoclavagem como tratamento térmico da

Tabela 1. Composição centesimal da farinha de soja integral (FSI), farinha de soja integral autoclavada (FSIA) e das farinhas de soja fermentadas em diferentes condições de temperatura e tempo de incubação (FSIAF), em base seca.

\begin{tabular}{|c|c|c|c|c|c|c|}
\hline \multirow{2}{*}{ Parâmetros } & \multirow{2}{*}{ FSI } & \multirow{2}{*}{ FSIA } & \multicolumn{2}{|c|}{ FSIAF a $30^{\circ} \mathrm{C}$} & \multicolumn{2}{|c|}{ FSIAF a $40^{\circ} \mathrm{C}$} \\
\hline & & & 24 horas & 48 horas & 24 horas & 48 horas \\
\hline Umidade (\%) & $8,91 \pm 0,06^{a}$ & $9,00 \pm 0,03^{a}$ & $9,22 \pm 0,10^{a}$ & $8,36 \pm 0,11^{a}$ & $8,60 \pm 0,09^{a}$ & $9,86 \pm 0,51^{a}$ \\
\hline Proteínas (\%) & $35,53 \pm 0,24^{b}$ & $35,06 \pm 0,15^{b}$ & $35,63 \pm 0,98^{b}$ & $38,63 \pm 0,01^{a}$ & $36,34 \pm 0,34^{b}$ & $37,21 \pm 0,17^{a}$ \\
\hline Lipídeos (\%) & $25,60 \pm 0,06^{b}$ & $25,52 \pm 0,04^{b}$ & $26,64 \pm 1,78^{a}$ & $27,07 \pm 0,57^{a}$ & $24,88 \pm 0,31^{b}$ & $26,58 \pm 1,06^{a}$ \\
\hline Cinzas (\%) & $4,81 \pm 0,06^{a}$ & $4,86 \pm 0,03^{a}$ & $4,48 \pm 0,03^{a}$ & $5,16 \pm 0,01^{a}$ & $4,82 \pm 0,04^{a}$ & $4,93 \pm 0,02^{a}$ \\
\hline Carboidratos* (\%) & $34,06 \pm 0,05^{a}$ & $34,56 \pm 0,06^{a}$ & $32,93 \pm 0,59^{b}$ & $29,14 \pm 0,16^{c}$ & $33,96 \pm 0,19^{b}$ & $31,27 \pm 0,43^{b}$ \\
\hline Fibra bruta (\%) & $2,49 \pm 0,41^{b}$ & $2,46 \pm 0,19^{b}$ & $2,92 \pm 0,08^{a}$ & $3,32 \pm 0,12^{a}$ & $2,99 \pm 0,16^{a}$ & $3,35 \pm 0,30^{a}$ \\
\hline
\end{tabular}

Médias aritméticas de três repetições \pm desvio padrão seguidas de mesma letra minúscula na linha não diferem entre si, pelo teste de Tukey $(p<0,05)$. *Calculado por diferença [100 - (proteína bruta + lipídeos + cinzas)], incluindo a fração de fibra bruta. 
soja e observaram resultados de composição centesimal semelhantes aos encontrados neste estudo.

No entanto, observa-se que o processo de fermentação promoveu alterações na composição físico-química e nutricional da farinha de soja integral autoclavada fermentada. De modo geral, não houve alteração nos teores de cinzas, fibras e umidade, porém ocorreu um aumento significativo nos teores de proteínas e lipídeos, e redução nos teores de carboidratos, quando comparados com os valores obtidos nas FSI e FSIA. Este comportamento pode ser explicado pelo metabolismo do fungo Aspergillus oryzae que, por meio da produção de enzimas hidrolíticas, degrada carboidratos complexos como fonte de energia para o seu crescimento, com consequente produção de proteínas e lipídeos estruturais, reduzindo a proporção de carboidratos e aumentando a proporção dos demais componentes da composição centesimal (CARLILE et al., 2001).

Feng et al. (2007) avaliaram a composição química da farinha de soja fermentada com Aspergillus oryzae por 48 horas e encontraram um aumento de 6,0\% nos teores de proteínas. Hong et al. (2004) avaliaram o efeito da fermentação da farinha de soja utilizando Aspergillus oryzae GB-107, por 48 horas, na qualidade nutricional e observaram um aumento nos teores de proteínas e de lipídeos após a fermentação. Os autores atribuíram este incremento de proteínas e lipídeos na farinha de soja fermentada à redução nos teores de carboidratos.

\subsection{Parâmetros tecnológicos}

A qualidade tecnológica da farinha de soja integral é o parâmetro de maior importância para as indústrias de matérias-primas e para os consumidores desse produto. Além da cor, estão incluídos nestes parâmetros a solubilidade da proteína, o índice de absorção de água, o índice de acidez do extrato etéreo, a atividade ureática e o pH (TAKEITI et al., 2004; LIU et al., 2008).

A cor da farinha de soja constitui um fator muito importante para sua comercialização e utilização como ingrediente em diversas formulações de produtos, sendo influenciada pelo tipo de processamento, ou seja, a aplicação de tratamento térmico utilizado para a redução e/ou eliminação dos compostos antinutricionais intensificou a coloração da farinha de soja (GIESE, 2000).

Observou-se que não houve variação significativa entre os parâmetros $L^{*}, b^{*}$ e $C^{*}$ da cor da FSI, quando comparados com os valores obtidos na FSIA; porém, houve uma redução no ângulo de tonalidade (hab) e um aumento no parâmetro $a^{*}$ da cor, o que não influenciou, de modo geral, na coloração das amostras de FSIA, no entanto intensificou a tonalidade amarela dessas amostras em relação à FSI (Tabela 2). A intensificação do parâmetro $a^{*}$ da cor da FSIA foi desenvolvida durante a autoclavagem, em função, provavelmente, de reações de caramelização dos açúcares e escurecimento não enzimático (reação de Maillard) (ZILIC et al., 2006).

Nas amostras de FSIAF, as condições de temperatura e tempo de incubação do processo de fermentação da FSIA, de modo geral, não influenciaram significativamente os parâmetros de cor $\left(L^{*}, a^{*}, b^{*}, C^{*}\right.$ e hab), mantendo as amostras com pouca variação nos valores de luminosidade, intensidade do amarelo e do vermelho, croma e ângulo de tonalidade, as quais apresentaram tendência à coloração amarela (Tabela 2). No entanto, quando comparados os valores dos parâmetros da cor das amostras de FSI e FSIA com os obtidos nas amostras de FSIAF, observou-se uma

Tabela 2. Parâmetros de cor determinados pelo sistema CIELab, propriedades tecnológicas, pH e IAU da farinha de soja integral (FSI), farinha de soja integral autoclavada (FSIA) e das farinhas de soja fermentadas em diferentes condições de temperatura e tempo de incubação (FSIAF).

\begin{tabular}{|c|c|c|c|c|c|c|}
\hline \multirow{2}{*}{ Parâmetros } & \multirow{2}{*}{ FSI } & \multirow{2}{*}{ FSIA } & \multicolumn{2}{|c|}{ FSIAF a $30^{\circ} \mathrm{C}$} & \multicolumn{2}{|c|}{ FSIAF a $40^{\circ} \mathrm{C}$} \\
\hline & & & 24 horas & 48 horas & 24 horas & 48 horas \\
\hline$L^{*}$ & $85,50 \pm 1,02^{a}$ & $83,90 \pm 0,16^{a}$ & $80,86 \pm 0,07^{b}$ & $79,94 \pm 0,07^{b}$ & $77,79 \pm 0,06^{b}$ & $77,92 \pm 0,10^{b}$ \\
\hline$a^{*}$ & $0,93 \pm 0,05^{d}$ & $2,08 \pm 0,04^{c}$ & $3,37 \pm 0,01^{b}$ & $4,28 \pm 0,05^{a}$ & $5,14 \pm 0,04^{a}$ & $5,24 \pm 0,05^{a}$ \\
\hline$b^{*}$ & $22,80 \pm 0,25^{b}$ & $23,52 \pm 0,09^{b}$ & $24,90 \pm 0,11^{a}$ & $26,26 \pm 0,12^{a}$ & $26,80 \pm 0,04^{a}$ & $27,39 \pm 0,07^{a}$ \\
\hline$C^{*}$ & $22,82 \pm 0,25^{b}$ & $23,61 \pm 0,10^{b}$ & $25,13 \pm 0,11^{a}$ & $26,61 \pm 0,61^{a}$ & $27,29 \pm 0,04^{a}$ & $27,89 \pm 0,08^{a}$ \\
\hline hab & $87,67 \pm 0,09^{a}$ & $84,96 \pm 0,08^{b}$ & $82,29 \pm 0,22^{c}$ & $80,74 \pm 0,06^{d}$ & $79,18 \pm 0,09^{d}$ & $79,16 \pm 0,08^{d}$ \\
\hline $\mathrm{pH}$ & $6,29 \pm 0,02^{a}$ & $6,27 \pm 0,03^{a}$ & $6,25 \pm 0,03^{a}$ & $6,41 \pm 0,01^{a}$ & $6,23 \pm 0,02^{a}$ & $6,23 \pm 0,07^{a}$ \\
\hline IAA $\left(m L \cdot g^{-1}\right)$ & $2,28 \pm 0,01^{a}$ & $1,84 \pm 0,03^{b}$ & $1,72 \pm 0,08^{b}$ & $1,81 \pm 0,06^{b}$ & $1,60 \pm 0,15^{c}$ & $1,67 \pm 0,03^{c}$ \\
\hline ISN (\%) & $82,86 \pm 0,79^{a}$ & $29,14 \pm 0,43^{c}$ & $32,94 \pm 1,46^{b}$ & $34,39 \pm 0,40^{b}$ & $24,63 \pm 1,07^{d}$ & $24,19 \pm 0,04^{d}$ \\
\hline IAE (mg KOH.g $\left.{ }^{-1}\right)$ & $0,08 \pm 0,01^{e}$ & $0,24 \pm 0,06^{d}$ & $0,99 \pm 0,01^{c}$ & $5,55 \pm 0,14^{a}$ & $0,58 \pm 0,04^{d}$ & $1,56 \pm 0,03^{b}$ \\
\hline $\mathrm{IAU}$ & $1,53 \pm 0,02^{a}$ & $0,61 \pm 0,14^{b}$ & $0,30 \pm 0,01^{c}$ & $0,26 \pm 0,08^{\circ}$ & $0,31 \pm 0,01^{\circ}$ & $0,26 \pm 0,11$ \\
\hline
\end{tabular}

Médias aritméticas de três repetiç̃es \pm desvio padrão seguidas de mesma letra minúscula na linha não diferem entre si, pelo teste de Tukey $(\mathrm{p}<0,05) ; \mathrm{FSI}=$ Farinha de soja integral; FSIA = Farinha de soja integral autoclavada; FSIAF = Farinha de soja integral autoclavada fermentada; Parâmetros de cor: $L^{*}$ Luminosidade, $+a^{*}$ - Vermelho, $+b^{*}$ - Amarelo, $C^{*}$ - Croma e hab - Ângulo de tonalidade; $\mathrm{pH}=$ Potencial hidrogênionico; IAA = índice de absorção de água; ISN = índice de solubilidade do nitrogênio; IAE = índice de acidez do extrato etéreo; IAU = índice de atividade ureática (unidade de $\mathrm{pH}$ ). 
redução dos parâmetros L* (luminosidade) e do ângulo de tonalidade (hab), com um aumento nos valores dos parâmetros $a^{*}, b^{*}$ e $C^{*}$, o que intensificou a tonalidade do vermelho e do amarelo dessas amostras.

Observou-se, na FSIA e nas amostras de FSIAF, uma redução nos índices de absorção de água, solubilidade do nitrogênio e atividade ureática, e um incremento nos valores de acidez do extrato etéreo. Não houve alteração nos valores de pH após a autoclavagem e a fermentação da farinha de soja integral (Tabela 2). $\mathrm{O}$ pH exerce forte influência sobre a funcionalidade das proteínas, visto que várias dessas propriedades funcionais dependem do estado de ionização de grupos ionizáveis na molécula proteica (TORREZAN e CRISTIANINI, 2005).

O índice de absorção de água (IAA) é uma propriedade relevante para aplicações em produtos como pães e bolos, pois valores elevados ajudam a manter a umidade destes produtos (RIAZ, 2006). A autoclavagem promoveu uma redução de 19,30\% nos valores de IAA (Tabela 2). Estudos realizados por Añón et al. (2001), que avaliaram o efeito do tratamento térmico no isolado proteico de soja, indicaram que este provocou a desnaturação das proteínas, reduzindo o IAA do isolado proteico de soja. Na FSIAF, houve uma redução no IAA em função da temperatura de incubação, sendo observados menores valores em amostras incubadas a $40{ }^{\circ} \mathrm{C}$ (Tabela 2). Este comportamento indica que as condições de fermentação influenciam esse parâmetro, em razão, provavelmente, da maior hidrólise das proteínas e da menor capacidade de absorção de água.

O índice de solubilidade do nitrogênio (ISN) é usado para se determinar a solubilidade das proteínas de alimentos, sendo reduzido pela desnaturação proteica. $\mathrm{Na}$ Tabela 2, os menores ISN foram observados nas amostras de FSIA, quando comparados aos de FSI, indicando que o tratamento térmico aplicado reduziu o ISN dessas amostras (ZILIC et al., 2006). Resultados semelhantes foram encontrados por Lemos et al. (1997), que estudaram o efeito do tratamento térmico do extrato hidrossolúvel de soja e observaram que a aplicação de $95{ }^{\circ} \mathrm{C}$ por 15 minutos reduziu o ISN de $90,57 \%$ para $25,31 \%$ na amostra termicamente tratada, em fução da desnaturação proteica.

O índice de solubilidade do nitrogênio apresentou variação significativa entre as amostras de FSI, FSIA e FSIAF (Tabela 2). Isto ocorreu em razão de a autoclavagem promover a redução do ISN da amostra de FSIA, pela desnaturação proteica. Verificou-se que as condições de fermentação utilizando-se Aspergillus oryzae, por 24 horas e 48 horas a $40^{\circ} \mathrm{C}$, não foram suficientes para promover a hidrólise das proteínas e aumentar o ISN; porém, a fermentação por 24 horas e 48 horas a $30^{\circ} \mathrm{C}$ possibilitou melhores condições para o fungo Aspergillus oryzae produzir enzimas proteolíticas, que hidrolisaram as proteínas desnaturadas, ocorrendo um aumento do ISN, quando comparado com a FSIA e FSIAF a $40{ }^{\circ} \mathrm{C}$, por 24 horas e 48 horas. Isto indica que as condições de fermentação também influenciaram o ISN da farinha de soja fermentada (HONG et al., 2004; TORREZAN e CRISTIANINI, 2005).

O índice de acidez do extrato etéreo (IAE) é uma variável que está relacionada com a qualidade da matéria-prima, com o processamento e, principalmente, com as condições de conservação dos lipídeos. Os lipídeos da FSI podem sofrer transformações químicas, como rancificação hidrolítica ou oxidativa, durante 0 armazenamento e no processamento (BOBBIO e BOBBIO, 2001).

Na autoclavagem, houve um aumento do IAE na FSIA, por causa de reações de rancidez hidrolítica não enzimáticas, as quais ocorrem em altas temperaturas, produzindo ácidos graxos livres e alterando a acidez do produto (CECCHI, 2003). No entanto, durante a fermentação, também houve um aumento no IAE, como já era esperado, em função das condições favoráveis para o fungo produzir enzimas que hidrolisam os lipídeos, produzindo ácidos graxos livres. Note-se, entretanto, que a alteração da acidez não ultrapassou o limite permitido pela legislação brasileira, que é de $2 \mathrm{~mL}$ de $\mathrm{KOH}(0,1 \mathrm{~N}) \cdot \mathrm{g}^{-1}$ de amostra, equivalente a $8 \mathrm{mg} \mathrm{KOH} \cdot \mathrm{g}^{-1}$ (ANVISA, 2005).

Nas indústrias de processamento de soja, o índice de atividade ureática (IAU) é utilizado com o objetivo de avaliar o efeito do tratamento térmico na qualidade nutricional, uma vez que a urease e os inibidores de tripsina apresentam um padrão similar de inativação (QIN et al., 1996). Este índice, após a autoclavagem, foi reduzido de 1,53 para 0,61 unidade de $\mathrm{pH}$, sendo que o processo de fermentação reduziu a atividade ureática de 0,61 na FSIA para 0,26 unidade de $\mathrm{pH}$ nas amostras de FSIAF a $30{ }^{\circ} \mathrm{C}$ e a $40{ }^{\circ} \mathrm{C}$, por 48 horas. Estes valores se encontram dentro da faixa considerada para inativação da enzima, que é de 0,05 a 0,30 unidade de pH (OLGUIN et al., 2003).

Estudos demonstraram que o processo de fermentação da soja reduz os níveis de inibidores de tripsina, melhorando seus aspectos nutricionais (HONG et al., 2004). Feng et al. (2007) observaram uma redução no teor do inibidor de tripsina na farinha de soja fermentada com o fungo Aspergillus oryzae, a $30^{\circ} \mathrm{C}$ por 48 horas, que passou de 2,6 mg. $\mathrm{g}^{-1}$ na farinha de soja não fermentada para $0,0 \mathrm{mg} \cdot \mathrm{g}^{-1}$ na farinha fermentada, possibilitando uma melhora na qualidade nutricional.

\section{Conclusões}

O processo de autoclavagem não influenciou significativamente a composição química da farinha de soja integral autoclavada, porém reduziu os índices de 
Caracterização físico-química e tecnológica da farinha de soja integral fermentada com Aspergillus oryzae SILVA, L. H. et al.

absorção de água, solubilidade do nitrogênio e atividade ureática, e aumentou o índice de acidez do extrato etéreo, não havendo alteração nos valores de pH, permitindo, dessa forma, sua utilização no processo de fermentação.

O aumento no tempo de fermentação influenciou a composição centesimal da farinha de soja integral autoclavada fermentada, promovendo incrementos nos teores de proteínas e lipídeos, e redução nos teores de carboidratos, não havendo alteração nos teores de cinzas, fibras e de umidade. Além disso, aumentou o índice de acidez do extrato etéreo, reduziu os índices de absorção de água, de solubilidade do nitrogênio e da atividade ureática da farinha de soja integral autoclavada fermentada, que passou de 0,61 (farinha de soja integral autoclavada) para 0,26 unidade de $\mathrm{pH}$ na farinha de soja integral autoclavada fermentada a $30{ }^{\circ} \mathrm{C}$ e a $40{ }^{\circ} \mathrm{C}$ por 48 horas. Indica-se, assim, a redução de fatores antinutricionais, porém o aumento no tempo de fermentação não influenciou na cor e no pH da farinha de soja integral autoclavada fermentada.

O processo de fermentação promoveu modificações nas propriedades físico-químicas, nutricionais e tecnológicas da farinha de soja integral, ampliando seu potencial de utilização na produção de alimentos mais saudáveis para o consumidor.

\section{Agradecimentos}

À FAPESP, pelo Auxílio Pesquisa, e ao CNPq, pela Bolsa de Doutorado.

\section{Referências}

AGÊNCIA NACIONAL DE VIGILÂNCIA SANITÁRIA - ANVISA. Resolução - RDC n 268, de 22 de setembro de 2005. Aprova o "Regulamento Técnico para Produtos Protéicos de Origem Vegetal". Diário Oficial da Bepública Federativa do Brasil, Brasília, DF, 23 set. 2005. Disponível em: <http://www.anvisa. gov.br/legis/resol>. Acesso em: 03 jul. 2012.

AGUIAR, C. L.; PARK, Y. K. Conversão de daidzina e genistina de soja por $\beta$-glucosidase de Aspergillus oryzae. Boletim do CEPPA, Curitiba, v. 22, n. 1, p. 185-195, 2004.

AMERICAN ASSOCIATION OF CEREAL CHEMISTS - AACC. Approved Methods American Association of Cereal Chemists. 10th ed. Saint Paul: AACC, 2000. v. 2.

AÑÓN, M. C.; SORGENTINI, D. A.; WAGNER, J. R. Relationships between Different Hydration Properties of Commercial and Laboratory Soybean Isolates. Journal of Agricultural Food and Chemical, Washington, v. 49, n. 10, p. 4852-4858, 2001. http://dx.doi.org/10.1021/jf010384s

BOBBIO, P. A.; BOBBIO, F. O. Química do Processamento de Alimentos. 3. ed. São Paulo: Varela, 2001. 143 p.
CARLILE, M. J.; WATKINSON, S. C.; GOODAY, G. W. The fungi. 2nd ed. New York: Academic Press, 2001. 608 p.

CECCHI, H. M. Fundamentos Teóricos e Práticos em Análise de Alimentos. 2. ed. Campinas: Ed. da Unicamp, 2003. 208 p.

COMPANHIA NACIONAL DE ABASTECIMENTO - CONAB.

Acompanhamento da Safra Brasileira: Grãos, Nono Levantamento (junho/2009). Brasília: CONAB, 2009. Disponível em: <http://www.conab.gov.br/conabweb/download/ safra/9graos_08.09.pdf> Acesso em: 05 jul. 2009.

FENG, J.; LIU, X.; XU, Z. R.; LU, Y. P.; LIU, Y. Y. The effect of Aspergillus oryzae fermented soybean meal on growth performance, digestibility of dietary components and activities of intestinal enzymes in weaned piglets. Animal Feed Science and Technology, New York, v. 134, n. 4, p. 295-303, 2007. http:// dx.doi.org/10.1016/j.anifeedsci.2006.10.004

GIESE, J. Color measurement in foods as a quality parameter. Food Technology, Chicago, v. 54, n. 2, p. 62-63, 2000.

HONG, K. J.; LEE, C. H.; KIM, S. K. Aspergillus oryzae GB-107 fermentation improves nutritional quality of food soybeans and feed soybean meals. Journal of Medicinal Food, New Rochelle, v. 7, n. 4, p. 430-436, 2004. http://dx.doi.org/10.1089/ jmf.2004.7.430

INSTITUTO ADOLFO LUTZ - IAL. Normas Analíticas do Instituto Adolfo Lutz: Métodos Químicos e Físicos para Análise de Alimentos. 3. ed. São Paulo: IAL, 1985. v. 1, 533 p.

LEMOS, J. L. S.; MELLO, M. C.; CABRAL, L. C. Estudo da solubilidade das proteínas de extratos hidrossolúveis de soja em pó. Ciência e Tecnologia de Alimentos, Campinas, v. 17, n. 3, p. 337-340, 1997. http://dx.doi.org/10.1590/S010120611997000300027

LIU, C.; WANG, X.; MA, H.; ZHANG, Z.; GAO, W.; XIAO, $L$. Functional properties of protein isolates from soybeans stored under various conditions. Food Chemistry, London, v. 111, n. 1, p. 29-37, 2008. http://dx.doi.org/10.1016/j. foodchem.2008.03.040

LIU, K. Soybeans as functional foods and ingredients. Columbia Missouri: AOCS Press, 2005. 331 p.

MACHADO, F. P. P; QUEIRÓZ, J. H.; OLIVEIRA, M. G. A.; PIOVESAN, N. D.; PELUZIO, M. C. G.; COSTA, N. M. B.; MOREIRA, M. A. Effects of heating on protein quality of soybean flour devoid of Kunitz inhibitor and lectin. Food Chemistry, London, v. 107, n. 2, p. 649-655, 2008. http://dx. doi. org/10.1016/j.foodchem.2007.08.061

MEJIA, E. G.; LUMEN, B. O. Soybean bioactive peptides: A new horizon in preventing chronic diseases. Sexuality, Reproduction and Menopause, New York, v. 4, n. 2, p. 91-95, 2006. http:// dx.doi.org/10.1016/j.sram.2006.08.012 
Caracterização físico-química e tecnológica da farinha de soja integral fermentada com Aspergillus oryzae SILVA, L. H. et al.

MINOLTA. Precise Color Communication: Color Control from Feeling to Instrumentation. Osaka: MINOLTA Co., Ltd., 1994. 49 p.

MOURA, N.; CANNIATTI-BRAZACA, S. G.; SOUZA, M. C.; DIAS, C. T. S. Composição de cultivares de soja submetida a diferentes tratamentos térmicos. Alimentação e Nutrição, Araraquara, v. 18, n. 2, p. 151-160, 2007.

OLGUIN, M. C.; HISANA, N.; D'OTTAVIO, A. E.; ZINGALE, M. I.; REVELANT, G. C.; CALDERARI, S. A. Nutritional and antinutritional aspects of an Argentinian soy flour assessed on weanling rats. Journal of Food Composition and Analysis, London, v. 16, n. 4, p. 441-449, 2003. http://dx.doi.org/10.1016/ S0889-1575(03)00005-X

PAMBOUKIAN, C. R. D. Influência das Condições de Preparo de Inóculo na Morfologia e na Síntese de Glicoamilase por Aspergillus Awamori. 1997. 189 f. Dissertação (Mestrado em Engenharia Química)-Escola Politécnica, Universidade de São Paulo, São Paulo, 1997.

PARK, Y. K.; AGUIAR, C. L.; ALENCAR, S. M. Biotransformação de isoflavonas de soja. Biotecnologia Ciência e Desenvolvimento, Brasília, v. 20, p. 12-14, maio/jun. 2001.

PAUCAR-MENACHO, L. M.; BERHOW, M. A.; MANDARINO, J. M G.; DE MEJIA, E. G.; CHANG, Y. K. Optimization of germination time and temperature on the concentration of bioactive compounds in Brazilian soybean cultivar BRS 133 using response surface methodology. Food Chemistry, London, v. 119, n. 2, p. 636-642, 2010. http://dx.doi.org/10.1016/j. foodchem.2009.07.011

PENHA, L. A. O.; FONSECA, I. C. B.; MANDARINO, J. M.; BENASSI, V. T. A soja como alimento: valor nutricional, benefícios para a saúde e cultivo orgânico. Boletim do CEPPA, Curitiba, v. 25, n. 1, p. 91-102, 2007.
QIN, G.; ELST, E. R.; BOSCH, M. W.; POEL, A. F. B. Thermal processing of whole soybeans: studies on the inactivation of antinutritional factors and effects on ileal digestibility in piglets. Animal Feed Science and Technology, New York, v. 57, n. 4, p. 313-324, 1996. http://dx.doi.org/10.1016/03778401(95)00863-2

RIAZ, M. N. Soy Applications in Food. London: Ed Taylor e Francis, 2006. 273 p.

SILVA, L. H.; CELEGHINI, R. M. S; CHANG, Y. K. Effect of fermentation of whole soybean flour in the isoflavone conversion from glycosides to aglycones. Food Chemistry, London, v. 128, n. 3, p. 640-644, 2011. http://dx.doi.org/10.1016/j. foodchem.2011.03.079

TAKEITI, C. Y.; SOUZA, A. S.; NETTO, F. M. Influência do tratamento térmico nas propriedades de solubilidade e de emulsificação de isolados protéicos de soja e de seus hidrolisados enzimáticos. Brazilian Journal of Food Technology, Campinas, v. 7, n. 1, p. 87-101, 2004.

TORREZAN, R.; CRISTIANINI, M. Revisão: efeito do tratamento sob alta pressão sobre as propriedades funcionais da proteína de soja e interação proteína-polissacarideos. Boletim do CEPPA, Curitiba, v. 23, n. 2, p. 201-220, 2005.

UNITED STATES DEPARTMENT OF AGRICULTURE - USDA. Agricultural Marketing Service. Brazil soybean transportation. Washington: USDA, 2009. Disponível em: <www.ams.usda.gov/ agtransportation> Acesso em: 05 jul. 2009.

ZILIC, S. M.; BOZÓVIC, I. N.; SAVIC, S.; SOBAJIC, S. Heat processing of soybean kernel and its effect on lysine availability and protein solubility. Central European journal of Biology. Poland, v. 1, n. 4, p. 572-583, 2006. http://dx.doi.org/10.2478/ s11535-006-0039-x 